\section{Modeling Transport Rates in Lake Baikal: Gas Exchange and Deep Water Renewal}

\author{
F. PEETERS, ${ }^{\dagger}$ R. KIPFER, $*, \dagger$ \\ R. HOHMANN, ${ }^{\dagger} M$. HOFER, ${ }^{\dagger}$ \\ D. $M$. IMBODEN, ${ }^{\dagger} G, G$. KODENEV, $\neq A N D$ \\ T. KHOZDER $\S$
}

Swiss Federal Institute of Technology (ETH) and Swiss Federal Institute for Environmental Science and Technology (EAWAG), $\mathrm{CH}-8600$ Dübendorf, Switzerland, Design and Technology Institute for Geophysical and Ecological Engineering, Siberian Division of the Russian Academy of Sciences, Novosibirsk 630090, Russia, and Limnological Institute of the Siberian Division of the Russian Academy of Sciences, Irkutsk 664033, Russia

Conc entrations of molecular oxygen in Lake Baikal (Eastern Siberia), the deepest lake on earth (1634 m), are above $80 \%$ saturation in the whole water column suggesting fast deep-water renewal. A model is developed to describe vertical water exchange based on measured concentrations of tritium, ${ }^{3} \mathrm{He}$, and the chlorofluoroc arbons $\mathrm{CFC}-11\left(\mathrm{CCl}_{3} \mathrm{~F}\right)$ and CFC-12 $\left(\mathrm{CCl}_{2} \mathrm{~F}_{2}\right)$. Lake Baikal consists of three main basins (south, central, north) that are separated by sills reaching up to about $300 \mathrm{~m}$ depth. Each basin is vertically divided into two boxes: a surface box $300 \mathrm{~m}$ thick and a deepwater box below $300 \mathrm{~m}$. Tracers are transported from/ into the surface layer by gas exchange with the atmosphere during ice-free periods, by precipitation, by evaporation, and by rivers. The tracer distribution in the lake depends primarily on the three intrabasin vertical water exchange rates. These rates are simultaneously fitted by modeling the four tracers from 1900 to the present. M ean residence times in the south, central, and north basins are $11.2 \pm 0.6$, $10.4 \pm 0.5$, and $6.2 \pm 0.5 \mathrm{yr}$, respectively. Application of the transport model to measured oxygen concentrations yields $\mathrm{O}_{2}$ consumption rates in all deep-water boxes of $0.1 \mathrm{mg}$ $\mathrm{L}^{-1} \mathrm{yr}^{-1}$.

\section{Introduction}

Lake Baikal (Siberia) is the world's largest and deepest freshwater body (Figure 1, Table 1). It is the habitat of numerous endemic species that were able to develop during the several million years of Lake Baikal's existence. The ecosystem is adapted to the extreme conditions that prevail in Lake Baikal: Several month of ice cover, large water depth, and very low nutrient concentrations. Industrial growth in the drainage area of the lake poses a potential threat to the unique aquatic ecosystem. In December 1996, Lake Baikal has been assigned an area of 'world heritage' by UNESCO.

The long-term protection of Lake Baikal and the design of a sustainable industrial development requires an under-

\footnotetext{
* Corresponding author fax: +41 1823 5028; e-mail: rolf.kipfer@ eawag.ch.

$\dagger$ ETH and EAWAG.

₹ Design and Technology Institute for Geophysical and Ecological Engineering.

$\S$ Limnological Institute.
}

Konstanzer Online-Publikations-System (KOPS)

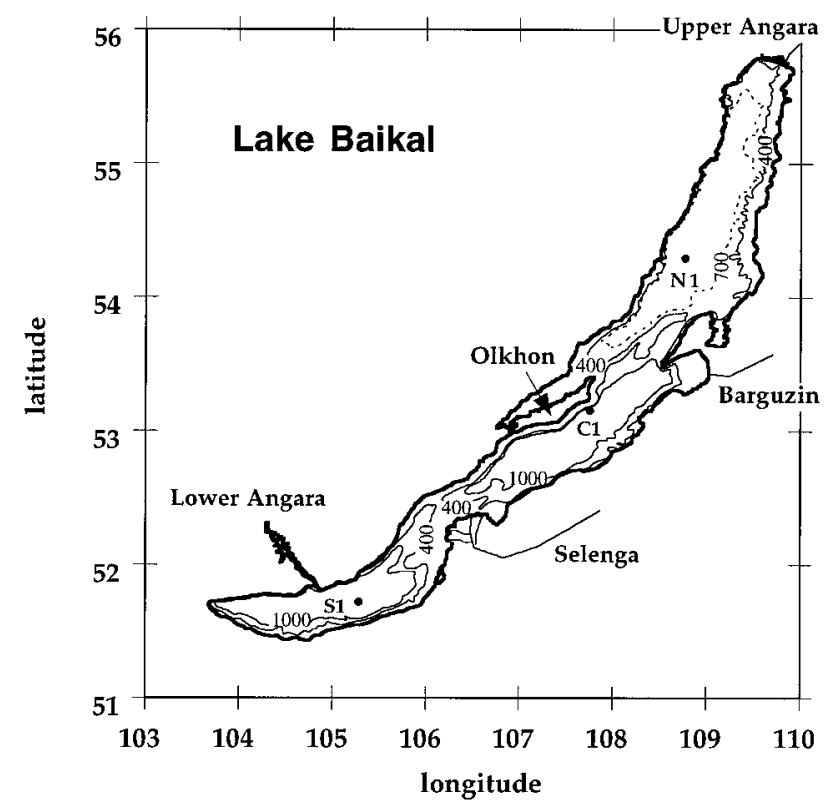

FIGURE 1. M ap of Lake Baikal. The lake is divided into south, central, and north basins as indic ated by the isobath at 400 and $1000 \mathrm{~m}$ depth. In the north basin, the $700 \mathrm{~m}$ isobath is included (dotted line). S1, $\mathrm{Cl}$, and N1 mark the deepest point of each basin. The Selenga, Upper Angara, and Barguzin Rivers are the main inlets, and the Low er Angara River at the southw estern end of the lake the only outlet. The south and central basins are separated by the Selenga delta. The central and north basins are separated by the topographic height (called Academician Ridge) that extends in northeastern direction from Olkhon Island.

TABLE 1. Characteristic Properties of Lake Baikal

surface area $\left(\mathrm{km}^{2}\right)$ area of cross-section in

$300 \mathrm{~m}$ depth $\left(\mathrm{km}^{2}\right)$

vol of surface layer $\left(\mathrm{km}^{3}\right)$

vol of deep-water layer $\left(\mathrm{km}^{3}\right)$

mean annual wind

velocity $\left(\mathrm{m} \mathrm{s}^{-1}\right)$

total annual evaporation $\left(\mathrm{km}^{3} \mathrm{yr}^{-1}\right)$

total annual precipitation $\left(\mathrm{km}^{3} \mathrm{yr}^{-1}\right)$

total annual river inflow $\left(\mathrm{km}^{3} \mathrm{yr}^{-1}\right)$

total annual outflow $\left(\mathrm{km}^{3} \mathrm{yr}^{-1}\right) \quad Q_{0} \quad \begin{array}{llll}59.8 & 39.3 & 13.5\end{array}$

mean of surface water temp from May to December $\left({ }^{\circ} \mathrm{C}\right)$

mean of air temp from May to December $\left({ }^{\circ} \mathrm{C}\right)$

mean date of freeze-up (from long-term observation) mean date of ice breakup mean duration of ice covering (days)

\begin{tabular}{|c|c|c|c|}
\hline & $\begin{array}{l}\text { south } \\
\text { basin }\end{array}$ & $\begin{array}{l}\text { central } \\
\text { basin }\end{array}$ & $\begin{array}{l}\text { north } \\
\text { basin }\end{array}$ \\
\hline $\begin{array}{l}A_{\mathrm{S}} \\
A_{\mathrm{D}}\end{array}$ & $\begin{array}{l}7381 \\
5762\end{array}$ & $\begin{array}{l}10469 \\
8052\end{array}$ & $\begin{array}{l}13621 \\
10754\end{array}$ \\
\hline $\begin{array}{l}V_{S} \\
V_{D} \\
U_{10}\end{array}$ & $\begin{array}{l}1901 \\
4327 \\
4.7\end{array}$ & $\begin{array}{l}2669 \\
6274 \\
5.0\end{array}$ & $\begin{array}{l}3549 \\
4295 \\
3.5\end{array}$ \\
\hline$E A_{\mathrm{S}}$ & 3.24 & 4.61 & 5.99 \\
\hline$Q_{P}$ & 2.89 & 4.12 & 5.35 \\
\hline$Q_{\mathrm{R}}$ & 20.8 & 26.3 & 14.1 \\
\hline $\begin{array}{l}Q_{\mathrm{o}} \\
T_{\mathrm{w}}\end{array}$ & $\begin{array}{l}59.8 \\
5.8\end{array}$ & $\begin{array}{l}39.3 \\
5.6\end{array}$ & $\begin{array}{l}13.5 \\
4.9\end{array}$ \\
\hline$T_{\text {air }}$ & 3.1 & 2.1 & 0.9 \\
\hline & J an 10 & J an 5 & J an 2 \\
\hline & $\begin{array}{l}\text { May } 4 \\
114\end{array}$ & $\begin{array}{l}\text { May } 11 \\
126\end{array}$ & $\begin{array}{l}\text { May } 18 \\
136\end{array}$ \\
\hline
\end{tabular}

standing of how substances entering the water are distributed and transformed within the lake. In this respect, an important observation made in Lake Baikal is the rather fast renewal of deep water as indicated by the large degree of saturation of dissolved oxygen throughout the water column, by thevertical distribution of water temperature, the light helium isotope ${ }^{3} \mathrm{He}$, tritium ${ }^{3} \mathrm{H}$, and theman-made chlorofluorocarbons CFC$11\left(\mathrm{CCl}_{3} \mathrm{~F}\right)$ and $\mathrm{CFC}-12\left(\mathrm{CCl}_{2} \mathrm{~F}_{2}\right)$ (Figure2). Thespecific shapes 
of the concentration profilessuggest that deep-water renewal cannot be accomplished by turbulent diffusion alone. Convective transport is required to generate the typical increase of CFC-11, CFC-12, and $\mathrm{O}_{2}$ in the deepest layer of each of the three major basins combined with a decrease of temperature and ${ }^{3} \mathrm{He}(1,2)$.

Several mechanisms have been proposed to explain the observed large-scale vertical water exchange: (a) Shimaraev et al. (3) argue that vertical convection is triggered in spring by the so-called thermal bar, i.e., at the locations where the surface water reaches $4{ }^{\circ} \mathrm{C}$, the temperature of maximum density at atmospheric pressure. Yet, a more detailed analysis constrains this kind of convection to the top $500 \mathrm{~m}$ (4). (b) Weiss et al. (1) and Killworth et al. (5) propose a combination of the thermobaric effect with wind-induced convection. (c) Experimental data by Hohmann et al. (2) give evidence for sal inity-driven convection at river inflows and at sills between basins. These authors have shown that in spring density currents induced by the Selenga River propagate through an underwater canyon (Kukui Canyon) to the deep layers of the lake and that density currents can also form at Academician Ridge where waters of different composition from the north and central basins meet.

Although each of the proposed processes is governed by different physical mechanisms, they all cause water masses to sink to larger depth. The sinking plumes influence the tracer concentrations in the lake in that they act as a source of water that has the characteristics of surface water. In other words, substances such as CFC-11, CFC- $12,{ }^{3} \mathrm{H},{ }^{3} \mathrm{He}$, and $\mathrm{O}_{2}$ are directly transported from the surface to deeper parts of the lake, thus bypassing intermediate layers. The 'mixing around the edge' explains the typical vertical structure of water age according to which the deepest water often appears to be younger than the water at intermediate depths $(1,6)$.

Several authors have estimated the average time needed to renew the deep water in Lake Baikal (see Table 5). Based on ${ }^{3} \mathrm{H}-{ }^{3} \mathrm{He}$ measurements, Craig (7) obtained a maximum water age of $18 \pm 4 \mathrm{yr}$ for the central basin. From ${ }^{3} \mathrm{H}$ and ${ }^{3} \mathrm{He}$ profiles measured in 1992, 1993, and 1995, Hohmann et al. (6) determined maximum ${ }^{3} \mathrm{H}-{ }^{3} \mathrm{He}$ water ages of $14-17,16-$ 18, and 10-11 yr for the south, central, and north basins, respectively.

Weiss et al. (1) calculated water age profiles from CFC-12 measurements. Since in the top $250 \mathrm{~m}$ their CFC-12 concentrations were $18 \%$ undersaturated relative to atmospheric equilibrium, they increased their data correspondingly and obtained mean water ages of 14, 16, and $9 \mathrm{yr}$ for the bottom layers of the south, central, and north basins, respectively. The mean age of the total water mass below $250 \mathrm{~m}$ was given as $8 \mathrm{yr}$. Based on the same data set and on dissolved oxygen concentrations, Killworth et al. (5) developed a more refined advective-diffusivemodel to calculate vertical exchange rates in Lake Baikal. They assumed that oxygen concentrations are at steady state and that the vertical distribution of CFC-12 can be approximated by $\mathrm{C}=$ at $+\tilde{\mathrm{C}}(\mathrm{z})$ with a being constant and $\tilde{C}$ being independent of $t$. By fitting the modeled tracer concentrations (essentially oxygen and CFC-12) to their data, Killworth et al. obtained an upwelling rate of about $500 \mathrm{~km}^{3} \mathrm{a}^{-1}$ at $400 \mathrm{~m}$, a vertical turbulent diffusivity of order $10^{-6} \mathrm{~m}^{2} \mathrm{~s}^{-1}$, and an oxygen-consumption rate between 0.13 and $0.18 \mathrm{mg} \mathrm{L}^{-1} \mathrm{yr}^{-1}$. Their calculated water residence times are similar as those of Weiss et al.

In this study we estimate deep-water renewal rates by simultaneously modeling concentrations of CFC-11, CFC$12,{ }^{3} \mathrm{H}$, and ${ }^{3} \mathrm{He}$. The CFC-12 data set used by Killworth et al. (5) is completed by measurements of CFC- 11 and CFC-12 made in 1993 and 1995 and by helium and tritium data obtained during several expeditions on Lake Baikal in the years 1992-1995. Based on the calculated transport rates and measured oxygen concentrations, oxygen depletion rates are calculated for the deep water masses of the lake.

\section{The Model}

Model Compartmentsand Transport Processes. Thevertical temperature distribution in Lake Baikal (Figure 2a) suggests that in each basin two regions can be distinguished: a surface layer about $200-300 \mathrm{~m}$ thick that is subjected to seasonal convective mixing and a deep-water layer bel ow $300 \mathrm{~m}$ where temperature is approximately stationary. Therefore a simple multibox model is developed in which each basin is vertically subdivided into two compartments: a surface box extending from 0 to $300 \mathrm{~m}$ depth and a deep-water layer below $300 \mathrm{~m}$ (Figure 3). The surface layers of the three basins are horizontally coupled by diffusive exchange and advection. Since the three basins are separated by sills reaching up to about 300 m depth, no horizontal mixing takes placebetween adjacent deep-water basins. Vertical transport between surface and deep-water layer is modeled by basin-specific exchange velocities.

The following mass transfer processes couple Lake Baikal with its surroundings: Input by rivers, loss through the Lower Angara River (the only outlet), air/ water exchange (including evaporation), and precipitation onto the lake surface. Although the existence of hydrothermal springs in the north basin has been well documented (8), groundwater exchange from and into the lake is assumed to be negligible for both the water balance as well as for the balance of the tracers. However, the helium isotope concentrations are corrected for the input of radiogenic helium from the crust.

At steady state, the water budget for the surface layer $b=$ $\mathrm{s}, \mathrm{c}$, and $\mathrm{n}$ (south, central, and north basins) is given by

$$
\mathrm{Q}_{\mathrm{Rb}}+\mathrm{Q}_{\mathrm{Pb}}+\mathrm{Q}_{\mathrm{Bb}}-\mathrm{Q}_{\mathrm{Ob}}+\mathrm{E}_{\mathrm{b}} \mathrm{A}_{\mathrm{b}}=0
$$

with $\mathrm{Q}_{\mathrm{Rb}}, \mathrm{Q}_{\mathrm{Pb}}$, and $\mathrm{Q}_{\mathrm{ob}}$ being, respectively, the rate of river inflow, precipitation onto the water surface, and outflow through the outlet or into the adjacent downstream basin. $\mathrm{Q}_{\mathrm{Bb}}$ is the net flow from the adjacent upstream basin, i.e., $\mathrm{Q}_{\mathrm{Bn}}$ $=0, \mathrm{Q}_{\mathrm{BC}}=\mathrm{Q}_{\text {on }}$, and $\mathrm{Q}_{\mathrm{Bs}}=\mathrm{Q}_{\mathrm{Oc}}$ (see Figure 3). Evaporation is accounted for by $E_{b} A_{b}$ where $E_{b}$ is the evaporation rate and $A_{b}$ is the surface area of the basin.

The chemical tracers are transported by both the unidirectional flow rates of eq 1 as well as by the bidirectional exchange rates described by the horizontal and vertical turbulent velocities $v_{h}$ and $v_{v}$, respectively. The horizontal exchange velocity between all basins is estimated from Okubo's (9) diffusion diagram to be on the order $v_{h}=30 \mathrm{~km}$ $\mathrm{yr}^{-1}$, which for a typical length scale of $100 \mathrm{~km}$ corresponds to a horizontal diffusion coefficient of order $100 \mathrm{~m}^{2} \mathrm{~s}^{-1}$. As it turns out, the model calculations are not very sensitive to the exact size of $v_{h}$ since horizontal gradients between the three surfacelayers remain small. This is not the casefor the vertical turbulent exchange. The corresponding velocities $\mathrm{v}_{\mathrm{vs}}, \mathrm{v}_{\mathrm{vc}}$, and $\mathrm{v}_{\mathrm{v} n}$ are treated as independent fit parameters. Note that the total exchange of water (volume per unit time) is the product of the exchange velocity and the contact area between the corresponding boxes (see Figure 3).

Mass Balance of Tritium. The mass balance equation of tritium is formulated with the following assumptions: (a) tritium concentrations in precipitation and river inflow are identical and for all basins described by the same timedependent function $C_{P}$; (b) the tritium concentration in the water vapor $C_{A}$ is in equilibrium with the meteoric water $C_{P}$ : $C_{A}=\alpha C_{P}$, where $\alpha=0.9$ is the equilibrium isotopic fractionation factor for tritium; (c) the tritium concentration in the lake at the air/ water interface is equal to the mean tritium concentration in the surface layer $C_{s}$. Then the mass balance, e.g., in the surface layer of the central basin is given by (10) 

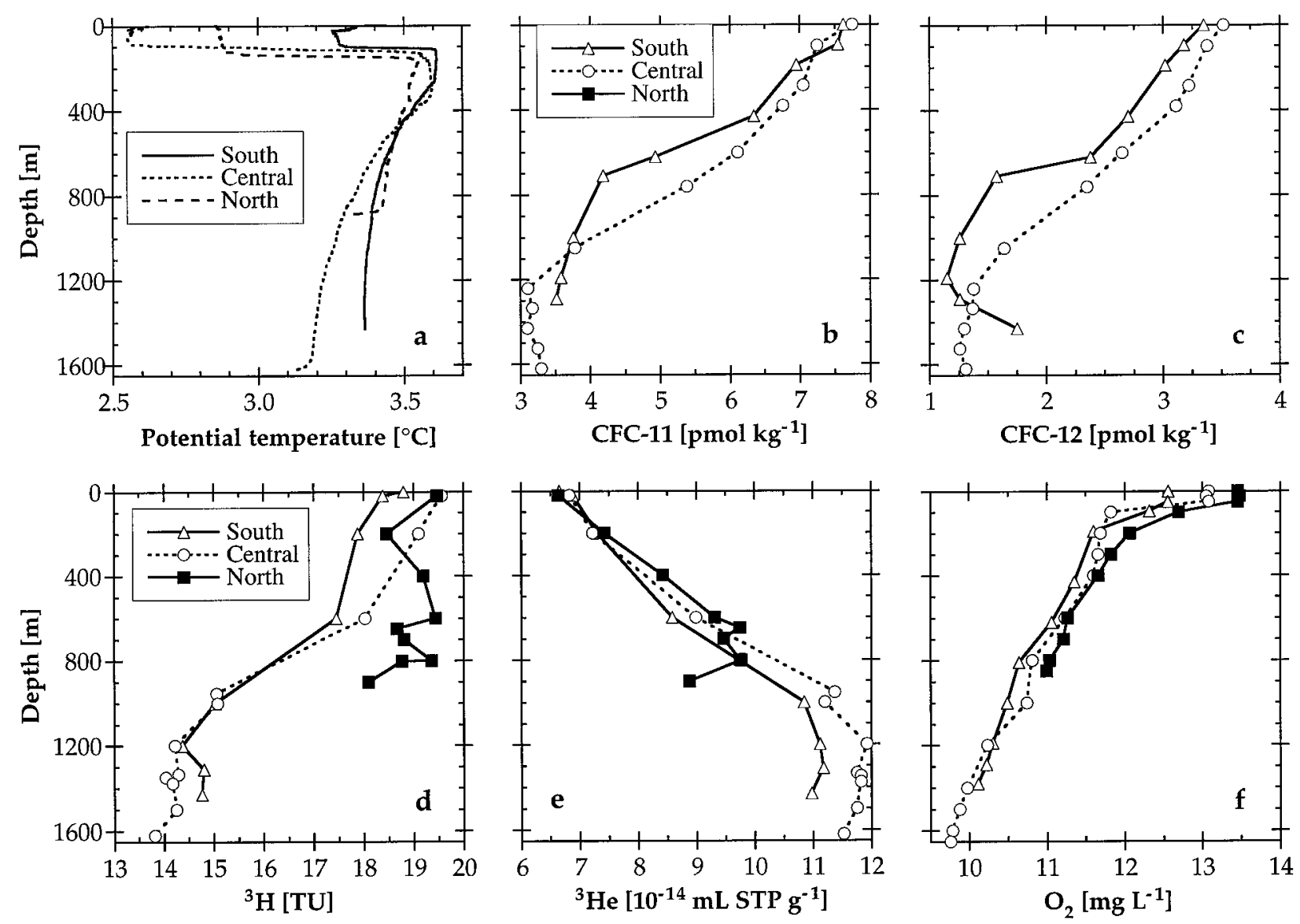

FIGURE 2. Vertical distribution of potential temperature and five gaseous tracers observed at the end of $M$ ay 1993 , about 2-4 weeks after ice breakup, at the deepest point of the south $(\triangle)$, central $(O)$, and north basins $(\square)$. These and similar profiles w ere used to calculate mean tracer concentrations for the six boxes show $n$ in Figure 3. ( $\left.\mathrm{mL} \mathrm{STP}^{-1}\right)$ is a concentration unit that is frequently used for noble gases. It stands for $1 \mathrm{~cm}^{3}$ of gas at standard temperature $\left(0^{\circ} \mathrm{C}\right)$ and pressure $(1 \mathrm{~atm})$ per gram of solution.

$$
\begin{aligned}
& V_{S c} \frac{\partial C_{S c}}{\partial t}=\left(Q_{R c}+Q_{P C}\right) C_{P c}+Q_{O n} C_{S n}- \\
& E_{c} A_{S c} \frac{\alpha\left(C_{S c}-h C_{P}\right)}{\alpha_{k}(1-h)}-Q_{O c} C_{S c}+v_{h} A_{h, c n}\left(C_{S n}-C_{S c}\right)+ \\
& v_{h} A_{h, c s}\left(C_{S s}-C_{S c}\right)+v_{v c} A_{D c}\left(C_{D c}-C_{S c}\right)-v_{S c} \lambda C_{S c}
\end{aligned}
$$

where $\alpha_{k}$ is the kinetic fractionation factor for tritium $\left(\alpha_{k}=\right.$ 1.1 , see ref 10$)$, and $\mathrm{h}$ is the relative humidity normalized to the water vapor saturation pressure at surface water temperature $e_{5}$. The decay constant of tritium is $\lambda=0.05576 \mathrm{yr}^{-1}$ (11). The definition of the other variables and the subscripts is given in Figure 3. The meaning of the right-hand side termsisasfollows: input by riversand precipitation; advective input from the north basin; input through water vapor exchange; advective loss to the south basin; turbulent exchange with the north basin, the south basin, and the deep central basin, respectively; and radioactive decay. For the deep-water layer, the balance is given by

$$
\mathrm{V}_{\mathrm{Dc}} \frac{\partial \mathrm{C}_{\mathrm{Dc}}}{\partial \mathrm{t}}=-\mathrm{v}_{\mathrm{vc}} \mathrm{A}_{\mathrm{Dc}}\left(\mathrm{C}_{\mathrm{Dc}}-\mathrm{C}_{\mathrm{Sc}}\right)-\mathrm{V}_{\mathrm{Dc}} \lambda \mathrm{C}_{\mathrm{Dc}}
$$

It is difficult to measure or estimate the relative humidity $\mathrm{h}$ over the lake surface. Yet according to Herczeg and Imboden (10), it can be expressed by the piston velocity $\mathrm{V}_{\mathrm{H}_{2} \mathrm{O}}$ of the vapor exchange between the water surface and the atmosphere and by the net evaporation $\mathrm{E}$ :

$$
\mathrm{h}=1-\frac{1}{\mathrm{v}_{\mathrm{H}_{2} \mathrm{O}}} \frac{\rho \mathrm{RT}_{\mathrm{air}} \mathrm{E}}{\mathrm{Me}}
$$

where $\rho=1000 \mathrm{~kg} \mathrm{~m}^{-3}$ is water density, $\mathrm{M}=0.018 \mathrm{~kg} \mathrm{~mol}^{-1}$ is the molecular weight of water, $\mathrm{R}=8.2 \times 10^{-5} \mathrm{~m}^{3} \mathrm{bar} \mathrm{mol}^{-1}$ $\mathrm{K}^{-1}$ is the gas constant, and $\mathrm{T}_{\text {air }}$ is the air temperature (in $\mathrm{K}$ ). The piston velocity as a function of wind speed $u_{10}$ (in $\mathrm{m} \mathrm{s}^{-1}$ ) can be approximated by (12)

$$
\mathrm{v}_{\mathrm{H}_{2} \mathrm{O}}=0.2 \mathrm{u}_{10}+0.3 \quad\left(\mathrm{~cm} \mathrm{~s}^{-1}\right)
$$

The saturation water vapor pressure $e_{5}$ is cal culated from the empirical equation of Krause (13):

$$
e_{s}=0.0061078 \times 10 \exp \frac{7.567 T_{w}}{239.7+T_{w}}
$$

where $T_{w}$ is the surface water temperature (in ${ }^{\circ} \mathrm{C}$ ).

Tritium concentrations in rain for the Lake Baikal region are reconstructed from IAEA time series (14) measured at several Russian stations (Irkutsk, Yakutsk, Novosibirsk, Omsk, Habarovsk, Enisejsk). Unfortunately, data for these stations areonly availablefor theyears 1969-1983. During this period, the Russian stations report tritium values in rain that are significantly larger than the values observed in Wien or Ottawa. This is probably due to the fallout from atmospheric nuclear tests carried out in northern China near Lake Baikal.

Following the procedure by Östlund (15), the data from the Russian stations are extrapolated to the years before 1969 and after 1983 by fitting them linearly to the datafrom Ottawa. The fit yields

$$
\mathrm{C}_{\mathrm{Tr}, \text { Baikal }}=23+1.15 \mathrm{C}_{\mathrm{Tr} \text {,Ottawa }}
$$

The Ottawa data represent the longest uninterrupted data set of tritium concentration in rain extending from 1953 to 


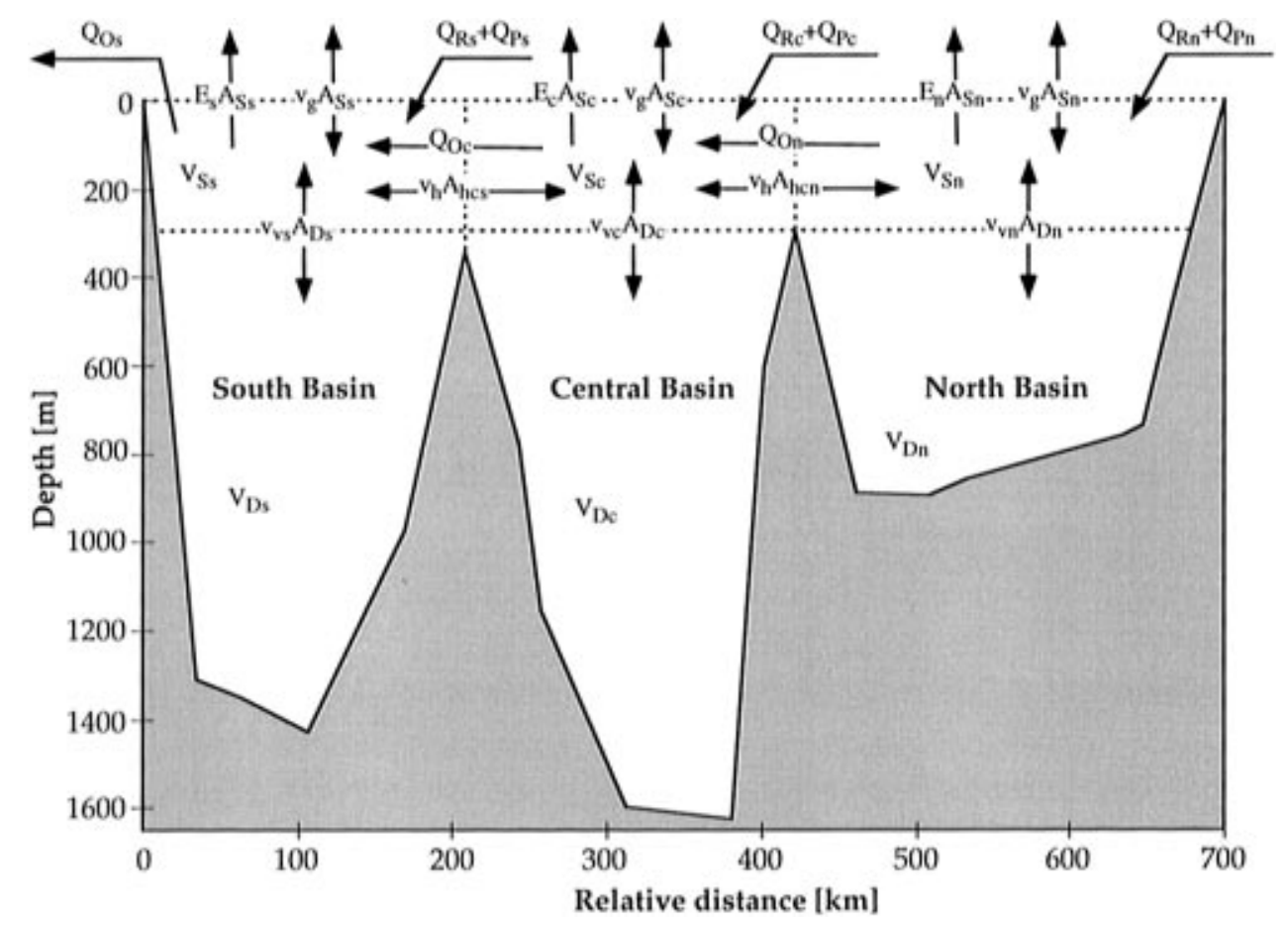

FIGURE 3. Simplified topographic picture of Lake Baikal along its central axis showing the division of the lake into six boxes (dashed lines). Simple arrow s indicate advective transport of water (described by mass fluxes $Q$ and evaporation rates $E$ ), double arrow $s$ indicate exchange fluxes (described by the product of an exchange velocity $v$ and an interface area $A$ ). Subscripts mean the following: $S$ and $D$, surface and deep (box); s, $c$, and $n$, south, central, and north basins; $R, P$, and 0 , river input, precipitation, and outflow; $h, v$, and $g$, horizontal, vertical, and air/w ater (exchange velocity).

1987. By assuming that the tritium concentration in rain is decreasing according to the law of radioactive decay since 1987, the Ottawa data set can be extrapolated to 1996. The prebomb tritium concentration in rain (before 1953) is taken as 5 TU $(16,17)$.

Mass Balance of ${ }^{3} \mathrm{He}$, CFC-11, CFC-12, and Dissolved Oxygen. The mass balance of other tracers than tritium can be described by equations similar to eq 2 . The mass balance for ${ }^{3}$ Hein the surface and deep-water box of the central basin serves as an example. Weassumethat the ${ }^{3} \mathrm{He}$ concentration in river and rainwater is at equilibrium with the atmospheric ${ }^{3} \mathrm{He}$ concentration and that these waters have the same temperature as the lake surface at any given time. The corresponding equilibrium concentration of $3 \mathrm{He}, \mathrm{C}_{\mathrm{Eb}}$, is calculated with the empirical equations given in Table 2 . In the following equation $\mathrm{C}$ means ${ }^{3} \mathrm{He}$ concentration and $\left[{ }^{3} \mathrm{H}\right]$ stands for tritium concentration.

$$
\begin{aligned}
& \mathrm{V}_{\mathrm{Sc}} \frac{\partial \mathrm{C}_{\mathrm{Sc}}}{\partial \mathrm{t}}=\left(\mathrm{Q}_{\mathrm{Rc}}+\mathrm{Q}_{\mathrm{Pc}}\right) \mathrm{C}_{\mathrm{Ec}}+\mathrm{Q}_{\mathrm{On}} \mathrm{C}_{\mathrm{Sn}}-\mathrm{v}_{\mathrm{g}, \mathrm{He}} \mathrm{A}_{\mathrm{Sc}}\left(\mathrm{C}_{\mathrm{Sc}}-\right. \\
& \left.C_{E c}\right)-Q_{O c} C_{S c}+v_{h} A_{h, c n}\left(C_{S n}-C_{S c}\right)+v_{h} A_{h, c s}\left(C_{S s}-C_{S c}\right)+ \\
& v_{v c} A_{D c}\left(C_{D c}-C_{S c}\right)+v_{S c} \lambda\left[{ }^{3} H\right]_{S c}(7 a) \\
& \mathrm{V}_{\mathrm{Dc}} \frac{\partial \mathrm{C}_{\mathrm{Dc}}}{\partial \mathrm{t}}=-\mathrm{v}_{\mathrm{vc}} \mathrm{A}_{\mathrm{Dc}}\left(\mathrm{C}_{\mathrm{Dc}}-\mathrm{C}_{\mathrm{SC}}\right)+\mathrm{V}_{\mathrm{Dc}} \lambda\left[{ }^{3} \mathrm{H}\right]_{D c}
\end{aligned}
$$

The notation is analogous to eq 2 . The last term in both equations describes the formation of ${ }^{3} \mathrm{He}$ by tritium decay. Note that the unit ( $\mathrm{mL} \mathrm{STP}^{-1}$ ), which is commonly used for ${ }^{3} \mathrm{He}$ concentrations, corresponds to $4.019 \times 10^{-14} \mathrm{TU}$.

The air/ water exchange of ${ }^{3} \mathrm{He}$, described by the third term on the right-hand side of eq $7 a$, is quantified by the exchange velocity $v_{g, H e}$. The gas exchange velocity is zero when the basins are ice covered. Due to the rather large Henry's law constants of all tracers considered in the model, the gas exchange is water-side controlled. Then, the exchange vel ocities of the different gases can be related to the exchange velocity of molecular oxygen, $\mathrm{v}_{\mathrm{O}_{2}}$, and to the ratio of the molecular diffusivities in water, $\mathrm{D}_{\text {gas }}$ and $\mathrm{D}_{\mathrm{O}_{2}}$, respectively (12):

$$
\begin{aligned}
v_{\text {gas }}=v_{\mathrm{O}_{2}}\left(\frac{D_{\text {gas }}}{D_{\mathrm{O}_{2}}}\right)^{0.5}, \text { with } \mathrm{v}_{\mathrm{O}_{2}}= & \\
4 & \times 10^{-4}+4 \times 10^{-5} \mathrm{u}_{10}^{2} \quad\left(\mathrm{~cm} \mathrm{~s}^{-1}\right)
\end{aligned}
$$

Diffusivity ratios are listed in Table 3. Wanninkhof (18) uses the Schmidt number, i.e., the ratio of viscosity and molecular diffusivity, to include the effect of water temperature. Yet, a sensitivity analysis showed that the model is not very sensitive to this kind of detail and that application of a more refined model is not justified.

The mass balance equations for CFC- 11 and CFC- 12 can be expressed by a modified version of eq 7 in which the input of ${ }^{3} \mathrm{He}$ due to tritium decay is omitted. Equilibrium concentrations of CFC- 11 and CFC- 12 as a function of time are calculated with the solubilities by Warner and Weiss (19) listed in Table 4. The atmospheric concentrations are given by Elkins et al. (20), Katz et al. (21), and Montzka et al. (22).

The mass balance of dissolved oxygen can also be modeled with a modified version of eq 7 . In this case, the radioactive decay terms must be replaced by oxygen depletion rates.

Fit Parameter and Model Implementation. To estimate deep-water renewal rates, all model parameters required to simulate CFC-11, CFC-12, tritium, and ${ }^{3} \mathrm{He}$ are determined in advance, except the three intra-basin vertical exchange velocities. The latter were obtained by minimizing $\chi^{2}$, the weighted least square difference between model output and measurements. $\chi^{2}$ was determined from simultaneous numerical iterations of the 24 mass balance equations, i.e., four tracers (CFC-11, CFC-12, ${ }^{3} \mathrm{H}$, and ${ }^{3} \mathrm{He}$ ) in each of the six boxes.

Oncetheexchangevelocities areknown, oxygen depletion rates are determined by treating exchange vel ocities as fixed and oxygen depletion rates as fit parameters. Comparison of simulated and measured oxygen concentrations provided oxygen depletion rates. 
TABLE 2. Empirical Relations To Calculate Helium Isotope Concentrations in Equilibrium with Air as a Function of Water Temperature

volume fraction of ${ }^{4} \mathrm{He}$ in air

Henry's law constant $H$ of ${ }^{4} \mathrm{He}$ in dry air at $1 \mathrm{~atm}$ as function of absolute temp $T$ (in $\mathrm{K}) ; H$ in $\left[(\mathrm{mL} \mathrm{STP})^{-1} \mathrm{~g} \text { atm }\right]^{a}$

${ }_{3}^{3} \mathrm{He} /{ }^{4} \mathrm{He}$ isotope ratio in air

${ }^{3} \mathrm{He} /{ }^{4} \mathrm{He}$ isotope fractionation a for solution in freshwater as a function of $T(\mathrm{~K})$

$$
\begin{aligned}
& 5.24 \pm 0.05 \mathrm{ppmV}(32) \\
& \operatorname{In}(1 / H)=a_{0}+a_{1} / T+a_{2} / T^{2} ; a_{0}=2.0517 ; \\
& \quad a_{1}=-4127.8 ; a_{2}=627250 ;(33) \\
& (1.384 \pm 0.006) \times 10^{-6}(34) \\
& \ln (a)=a_{0}+a_{1} / T+a_{2} / T^{2} ; a_{0}=-0.0299645 ; \\
& \quad a_{1}=19.8715 ; a_{2}=-1833.92 ;(35)
\end{aligned}
$$

${ }^{a}$ In the original work by Benson and Krause (33), the Henry's law constant is given in units [mol(He) ${ }^{-1}$ mol(Water) atm]. The multiplication factor between the units is $1\left[\mathrm{~mol}(\mathrm{He})^{-1} \mathrm{~mol}(\right.$ Water) $\mathrm{atm}]=8.037 \times 10^{-4}\left[(\mathrm{~mL} \mathrm{STP})^{-1} \mathrm{~g}\right.$ atm]. This factor was included in the empirical relation for $H$ by a corresponding adjustment of $a_{0}$.

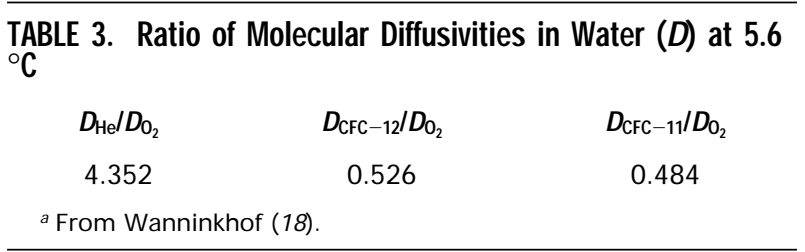

TABLE 4. Solubility F of CFC-12 and CFC-11 in Moist Air as a Function of Absolute Temperature T at a Total Pressure of 1 atm $^{\mathrm{a}}$

\begin{tabular}{ccccc} 
gas & $a_{1}$ & $a_{2}$ & $a_{3}$ & $a_{4}$ \\
CFC-12 & -220.2120 & 301.8695 & 114.8533 & -1.39165 \\
CFC-11 & -232.0411 & 322.5546 & 120.4956 & -1.39165 \\
\multicolumn{4}{c}{ a From Warner and Weiss $(19), \ln F=a_{1}+a_{2}(100 / T)+a_{3} \ln (T / 100)$} \\
$+a_{4}(T / 100)^{2} ; T$ in $(K), F$ in mol kg atm $^{-1}$. \\
\hline
\end{tabular}

The model is implemented with AQUASIM (23), which is a user-friendly program designed for the identification and simulation of aquatic systems in the laboratory, in technical plants, and in nature. In addition to allowing simulations of user-specified models, AQUASIM provides elementary methods for parameter estimation and uncertainty analysis. AQUASIM is very flexible with regard to model formulation and is particularly flexible in allowing the user to specify transformation processes. For further details on AQUASIM, see Reichert (23).

\section{Field Data}

Hydrological and morphological data of LakeBaikal aretaken from Shimaraev et al. (24) and are summarized in Table 1. They include surface areas and volumes of the basins, evaporation, precipitation and river discharge, mean wind velocities, and others. Monthly air temperatures were obtained by scaling monthly values from Irkutsk to agree with the 3-month average of air temperature recorded in the south, central, and north basins of Lake Baikal (24). The mean barometric pressure at thelake surface is 0.947 atm (1). Data on ice cover for the south basin were obtained from Shimaraev (personal communication). These data were extrapolated to the central and north basins by using the mean time differences between the lake basins of freeze-up and breakup given by Shimaraev et al. (24).

Vertical concentration profiles of temperatureand several chemical tracers are shown in Figure 2. The data were collected at the end of May 1993 at the deepest location of each basin, about $2-4$ weeks after ice breakup. These and similar profiles were used to calculate mean tracer concentrations for each of the six boxes.

Oxygen was measured by Winkler titration. ${ }^{3} \mathrm{H}$ and ${ }^{3} \mathrm{He}$ concentrations were determined from water samples collected in all basins in 1992, 1993, 1994, and 1995 and analyzed according to the technique described by Kipfer et al. (25). A detailed discussion is given by Hohmann et al. (6). Due to technical difficulties, ${ }^{3} \mathrm{H}$ data of 1994 could not be used.
Radiogenic ${ }^{3} \mathrm{Hefrom}$ the continental crust and ${ }^{3} \mathrm{Heintroduced}$ by air contamination of the samples has been subtracted from the ${ }^{3} \mathrm{He}$ data (6).

The data on chlorofluorocarbons (CFCS) originate from several sources. The CFC-12 measurements of 1988and 1991 weretaken from Weiss et al. (1) and Killworth et al. (5). Water samples were analyzed in thelaboratory of $\mathrm{R}$. Weissaccording to the method described by Bullister and Weiss (26). During an expedition in 1993 to the south and central basins, we collected water samples and had them analyzed for CFC-12 and CFC-11 (see Figure $2 b, c$ ) with an instrument developed in Novosibirsk in which a similar method as that of Bullister and Weiss is employed. In 1995, water samples were taken in the south basin and filled into copper tubes (as commonly used for helium samples). They were analyzed for CFC-11 and CFC-12 at EAWAG/ETH (Switzerland) using a vacuum extraction line (details in Hofer et al., in preparation).

\section{Results and Discussion}

Deep-Water ExchangeVelocities. Starting in 1900, themean concentrations of the tracers CFC-11, CFC-12, ${ }^{3} \mathrm{H}$, and ${ }^{3} \mathrm{He}$ were modeled simultaneously in all six boxes of the Lake Baikal model. The three vertical exchange velocities $\left(v_{v s}, v_{v c}\right.$, and $\left.v_{v n}\right)$, the only free model parameters, were chosen such as to minimize $\chi^{2}$ for all tracersin all boxes. Theoptimization is based on a total of 66 data points. Byassuming an absolute error for the mean concentration in each compartment of 1 TU for tritium and of $5 \%$ for the other tracers, the model is consistent with the data according to a $\chi^{2}$-test.

The resulting deep-water exchange velocities are $68 \pm 3$, $75 \pm 4$, and $64 \pm 5 \mathrm{~m} \mathrm{yr}^{-1}$ for the south, central, and north basins, respectively. They correspond to a volume flux $\mathrm{Q}_{\mathrm{ex}}$ of 390,600 , and $690 \mathrm{~km}^{3} \mathrm{yr}^{-1}$. By dividing the deep-water volumes by these fluxes, mean water residence times below $300 \mathrm{~m} \tau_{\text {ex }}$ become 11.2, 10.4, and $6.2 \mathrm{yr}$. These numbers are summarized in Table 5.

In Figure 4, model calculations and measurements are shown for both boxes of the central basin for the period from 1940 to present. The sharp increase of the CFCs (Figure4a,b) marks the rapid growth of the atmospheric CFC-11 and CFC12 concentration after 1940 (21). The positive concentration difference between surface and deep water indicates that deep-water renewal is not fast enough to transport CFC to the bottom of the lake at the same pace as atmospheric CFC concentrations were rising. Although measurements exist only since 1988, the absence of the CFCs prior to 1940 represents additional 'experimental' information, since concentrations in all boxes must initially have been zero.

A similar development is observed for tritium. Due to atmospheric nuclear bomb testing, its concentrations in rain increased dramatically in the 1950s and 1960s. Before 1950, the tritium concentration in rain was only about 5 TU (16, 17). At that time, tritium concentrations in Lake Baikal must have been at steady state determined by input from the rivers and the atmosphere and by radioactive decay in the lake. This value is extremely small and has only a minor influence on tritium concentrations in the early 1990s, the time of our tritium measurements (Figure 4c). 
TABLE 5. Vertical Water Exchange Rate and Water Age: Comparison of Results from Different Investigations

vertical exchange velocity, $v_{\mathrm{vb}}\left(\mathrm{m} \mathrm{yr}^{-1}\right)$

vol flux $Q_{\mathrm{ex}}\left(\mathrm{km}^{3} \mathrm{yr}^{-1}\right)$

residence time, $\tau_{\text {ex }}(\mathrm{yr})$

${ }^{3} \mathrm{H}-{ }^{3} \mathrm{He}$ water age (yr) (mean: 1988-1995)

CFC-12 water age (yr) (mean: 1988-1995)

oxygen depletion rate $\left(\mathrm{mg} \mathrm{L}^{-1} \mathrm{yr}^{-1}\right)$

${ }^{3} \mathrm{H}-{ }^{3} \mathrm{He}$ water age $(\mathrm{yr})$

Craig (7)

Hohmann et al. (6) $(h>250)$

CFC-12 water age (yr)

Weiss et al. (1) (adding 18\%, i.e., $5 \mathrm{yr}$ ) $(h>250 \mathrm{~m})$

oxygen depletion rate $\left(\mathrm{mg} \mathrm{L}^{-1} \mathrm{yr}^{-1}\right)$

Weiss et al. (1) $\quad(h>250 \mathrm{~m})$ (mid depth below $225 \mathrm{~m}$ )

Killworth et al. (5) $\quad(h>250 \mathrm{~m})$

Hohmann et al. (6) (max depth $200 \mathrm{~m}>h>200 \mathrm{~m}$ )

\begin{tabular}{lll}
\multicolumn{2}{c}{ basins } \\
\hline south & central north
\end{tabular}

This Investigation at $300 \mathrm{~m}$

for $h>300 \mathrm{~m}$

for $h>300 \mathrm{~m}$

deep-water layer

surface layer

age difference

deep-water layer

surface layer

age difference

Other Investigations

max value

max value

mean of each basin

$14-17$

$68 \pm 3$

$390 \pm 20$

$75 \pm 4$

$64 \pm 5$

11.8

1.4

10.4

14.1

5.2

8.9

0.10

$\begin{aligned} 600 & \pm 20 \\ 10.4 & \pm 0.5\end{aligned}$

$690 \pm 60$
$6.2 \pm 0.5$

8.0

11.1

1.5

6.5

10.4

5.0

13.5

5.0

8.5

0.10

5.4

0.11

max value

mean of all basins

14

$18 \pm 4$

10.7

10-11

10.2

7.4

from mean values

16

8

9 from linear regression

from model

from linear regression $0.14^{a}$

$0.12^{a}$

$0.13-0.18^{a}$

$0.13^{a}$

a Mean of all basins.
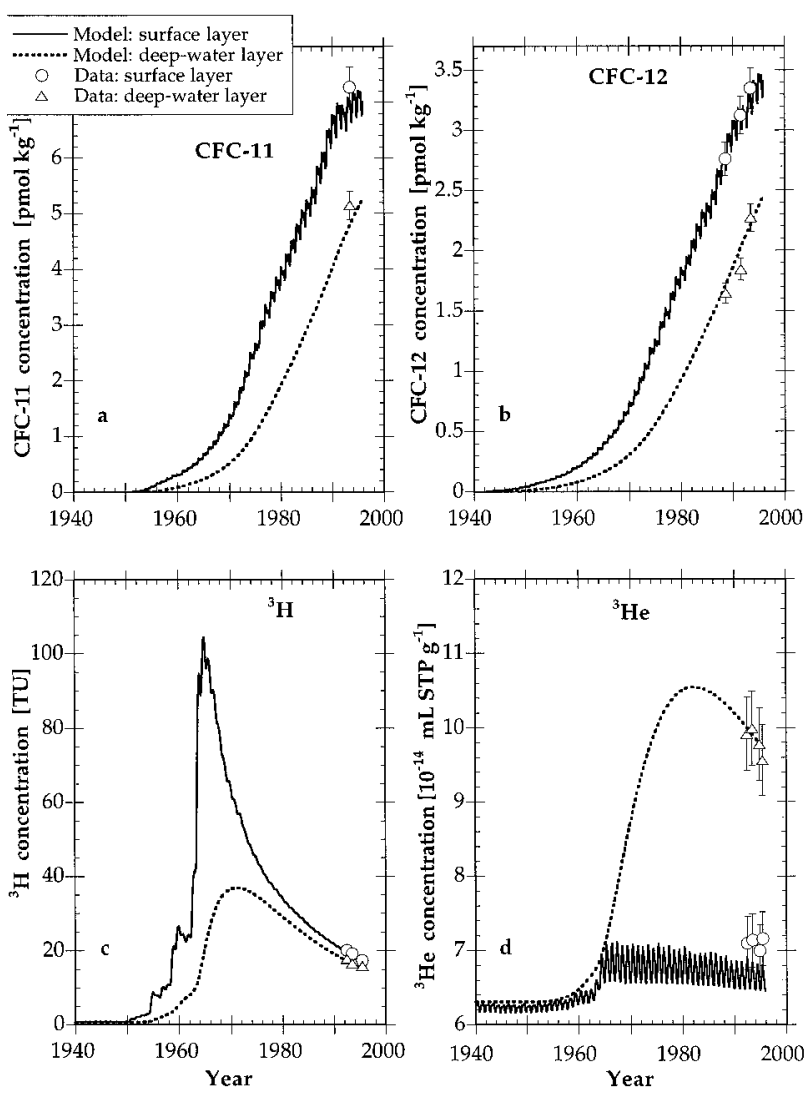

FIGURE 4. Comparison of model calculations and measurements of four tracers for the surface layer (solid line) and deep-w ater layer (dashed line) of the central basin for the period from 1940 to present. Spatial mean concentrations calculated from measurements are show $\mathrm{n}$ by the symbols $\bigcirc$ (surface layer) and $\Delta$ (deep-w ater layer).

The dynamics of ${ }^{3} \mathrm{He}$ is linked to the anthropogenic input history of tritium by radioactivedecay (Figure 4d). After 1950, tritium decay becamethe main source of ${ }^{3} \mathrm{He}$ in the lake. ${ }^{3} \mathrm{He}$ was continuously removed from the surface layer to the atmosphere by gas exchange, thus the excess helium concentration remained small. Since the exchange between surface and deep-water layer is slower than the exchange between surface layer and the atmosphere, ${ }^{3} \mathrm{Heconcentrations}$ in the deep layers increased continuously due to decay of tritium.

The surface concentration of ${ }^{3} \mathrm{He}$ shows annual oscillations, but its annual mean is fairly constant, except for the sudden increasein theearly 1960 s caused by thebomb tritium decay (Figure 4d). Such oscillations also appear in the modeled surface concentrations of the CFCs (Figure 4a,b). They arecaused byicecovering, which prohibits gas exchange, and by the seasonal variation of surface water temperature, which affects the solubility of the gases. These effects can be seen in an enlarged portion of the model calculation for CFC12 in the central basin (Figure 5). Periods of ice covering are marked in gray. After ice breakup, the surface water temperature is still low, and thus the equilibrium concentration of CFC-12 (dotted line in Figure 5) is large. Gas exchange causes transport of CFC-12 into thesurfacelayer, which results in an increase of the concentration in the surface layer (solid line). In the summer, surface temperature rises and the equilibrium concentration of CFC-12 sinks below the surface layer concentration thus causing loss of CFC-12 to the atmosphere. In late fall, water temperature becomes small again and the situation is similar as in spring. During ice covering, air/ water exchange is inhibited. CFC-12 in the surface layer drops due to loss to the deep-water layer by vertical mixing.

In order to test the sensitivity of the vertical exchange velocities obtained by the model fit, we analyze the relative influence of the various processes on the tracer mass balance. If, on one hand, vertical exchange appears to be important and, on the other hand, processes that are not known very well-such as horizontal mixing-turn out to be small, then the method is sensitive to the size of $v_{\mathrm{vb}}(b=s, c, n)$. Figure 6 shows the various modeled mass fluxes of CFC $-12,{ }^{3} \mathrm{H}$, and ${ }^{3} \mathrm{He}$ to and from the surface layer of the central basin.

The balance of CFC- 12 is dominated by the input by air/ water exchange and the loss to the deep layer by vertical 


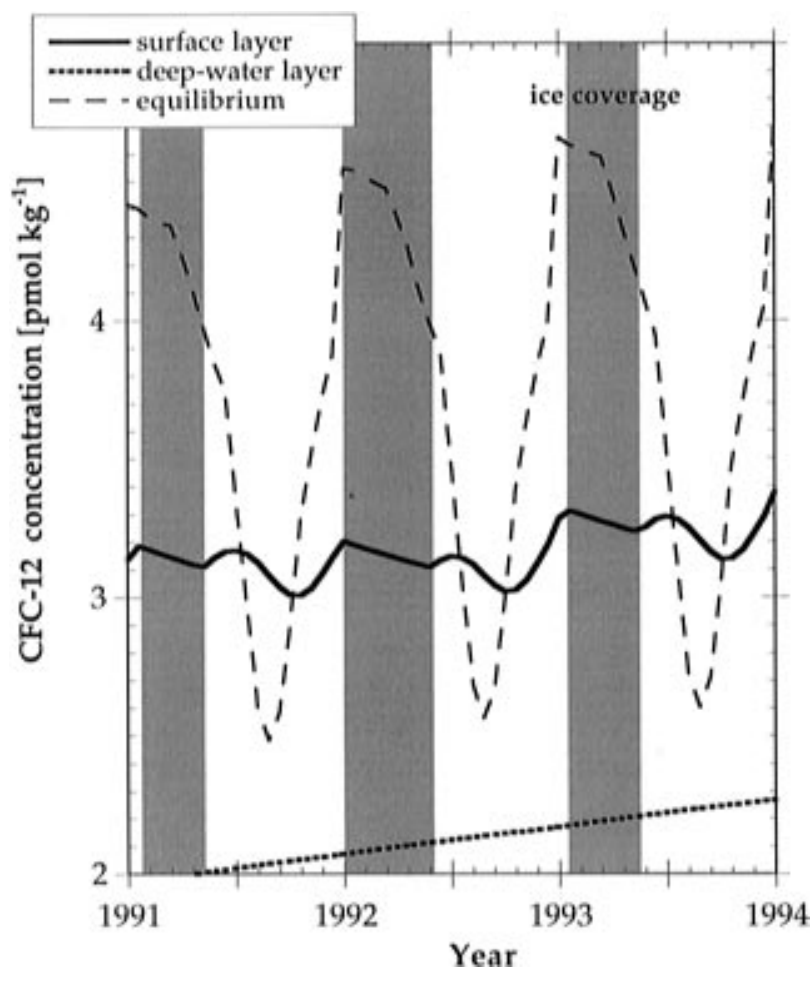

FIGURE 5. Enlarged portion of the model calculation for CFC-12 in the central basin. The seasonal variation of the atmospheric equilibrium concentration (thin dashed line) reflects the variation of surface water temperature (solubility of CFC-12 is large at low temperature). Ice covering (gray area) prohibits air/w ater exchange. During this period, CFC-12 is lost from the surface to the deep layers by vertical mixing.

mixing (Figure 6a). Horizontal transport is negligible. Decreasing the vertical mixing velocity $\mathrm{v}_{\mathrm{vc}}$ would cause a decrease of the transport of CFC-12 to the deep-water layer. Consequently, themodeled CFC-12 concentration in the deep-water layer would increase less than shown in Figure $4 b-$ in contradiction to the measurements. Therefore, the CFC- 12 data restrict the size of $\mathrm{v}_{\mathrm{vc}}$ fairly sensitively. The situation is similar for CFC-11.

For the case of tritium, the largest source is input by rivers followed by air/ water exchange of water vapor (Figure 6b). In the 1960s and 1970s, vertical transport to the deep-water layer wasthe most important removal processfrom the surface layer. Today, radioactive decay of ${ }^{3} \mathrm{H}$ is the dominant loss process (inset of Figure $6 \mathrm{~b}$ ). Since the input by rivers and water vapor exchange are linearly related to the same atmospheric forcing function, the sensitivity of the tritium data to the vertical exchange velocity $\mathrm{v}_{\mathrm{vc}}$ is similar as for the CFCs.

For ${ }^{3} \mathrm{He}$, different processes dominate the mass flux through the surface layer of Lake Baikal since 1940 (Figure $6 \mathrm{c})$ : While the ${ }^{3} \mathrm{He}$ flux was very small during the prebomb area, the input of ${ }^{3} \mathrm{He}$ increased sharply in the early $1960 \mathrm{~s}$ due to tritium decay. Today, the flux of ${ }^{3} \mathrm{He}$ from the deep layer by vertical mixing is the main source of ${ }^{3} \mathrm{He}$ in the surface layer. Gas exchange is the only relevant loss of ${ }^{3} \mathrm{He}$ from the lake.

To summarize, Figure 6 shows that among all internal processes deep-water exchange had (and still has) the largest influence on the tracer mass balance in the surface layer of LakeBaikal. Consequently, themodel prediction of thetracer concentrations must be sensitive to the rate of deep-water exchange.

Water Age. In the above model mean water residence time in the deep-water layers due to vertical exchange with the respective surface layers was calculated by dividing the layer volumes by the corresponding exchange fluxes. We
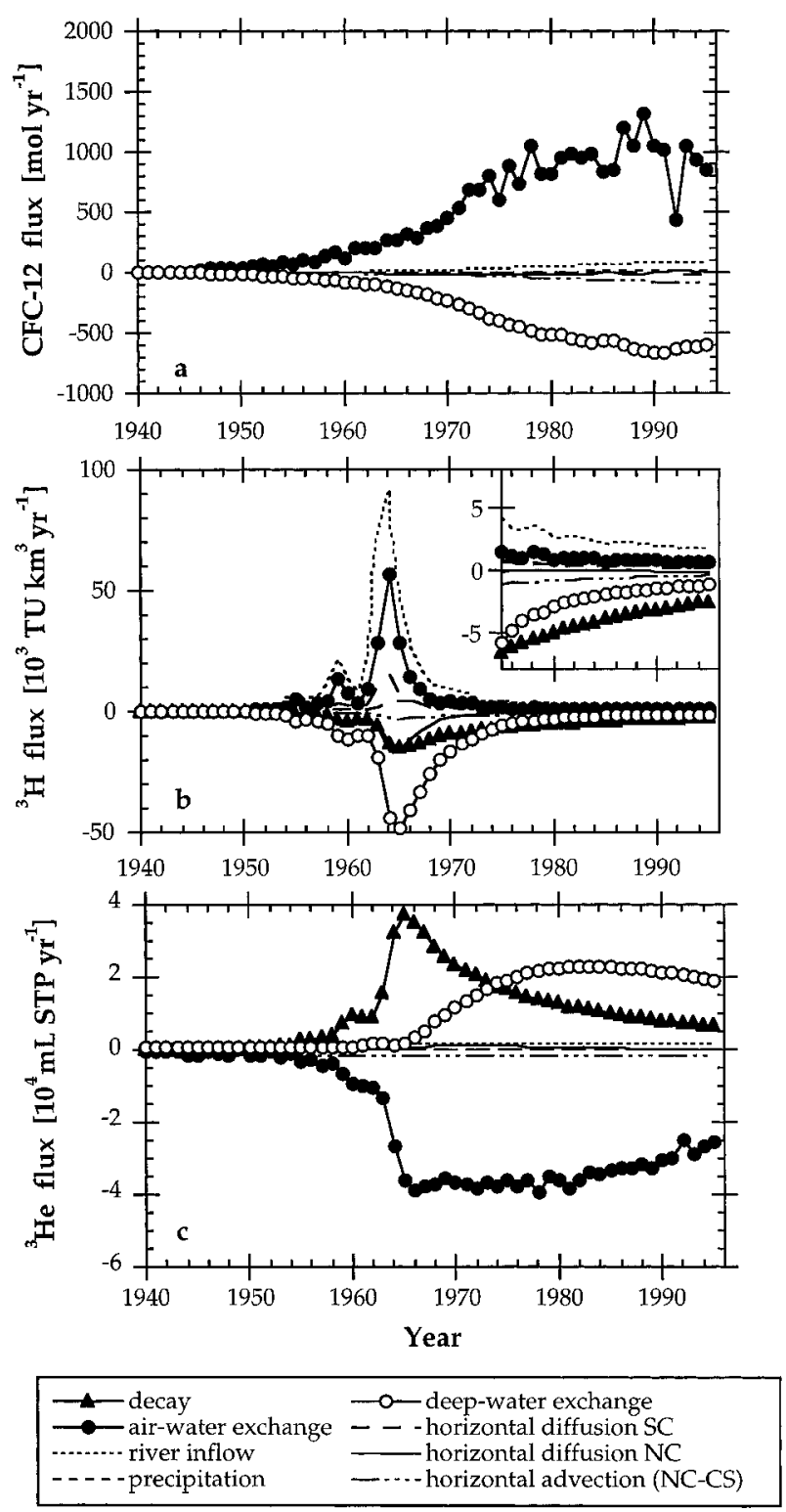

FIGURE 6. Contribution to the mean annual mass fluxes of CFC-12, ${ }^{3} \mathrm{H}$, and ${ }^{3} \mathrm{He}$ of the different transport and transformation processes in the surface layer of the central basin. Positive values characterize fluxes into the surface layer.

now want to compare this time with helium/ tritium age $\tau_{\mathrm{He}}$. This age is calculated based on the assumption that all excess ${ }^{3} \mathrm{He}$ measured in a given water volume has been produced by tritium decay in the same water volume. $\tau_{\mathrm{He}}$ is given by (27)

$$
\tau_{\mathrm{He}}=\frac{1}{\lambda} \ln \left(1+\frac{\left[{ }^{3} \mathrm{He}_{\mathrm{tri}}\right]}{\left[{ }^{3} \mathrm{H}\right]}\right)
$$

where $\left[{ }^{3} \mathrm{He}\right.$ tri] is the tritiogenic ${ }^{3} \mathrm{He}$, i.e., the measured ${ }^{3} \mathrm{He}$ minus the atmospheric equilibrium concentration.

As shown by Aeschbach-Hertig (28), $\tau_{\mathrm{He}}$ differs from the residencetimeif theinput of tritium is time-dependent. Figure $7 \mathrm{a}$ shows the temporal evolution of the 'apparent' ${ }^{3} \mathrm{H}-{ }^{3} \mathrm{He}$ water age for the central basin that was calculated from eq 9 using the concentrations obtained from the model calculation and from field data shown in Figure 4c,d. During the period of large tritium input, the calculated apparent water age in the deep box lies between 3 and $4 \mathrm{yr}$ and then rises to about $11 \mathrm{yr}$ when the temporal variations of ${ }^{3} \mathrm{H}$ and ${ }^{3} \mathrm{He}$ become small. Calculated water age in the surface layer 

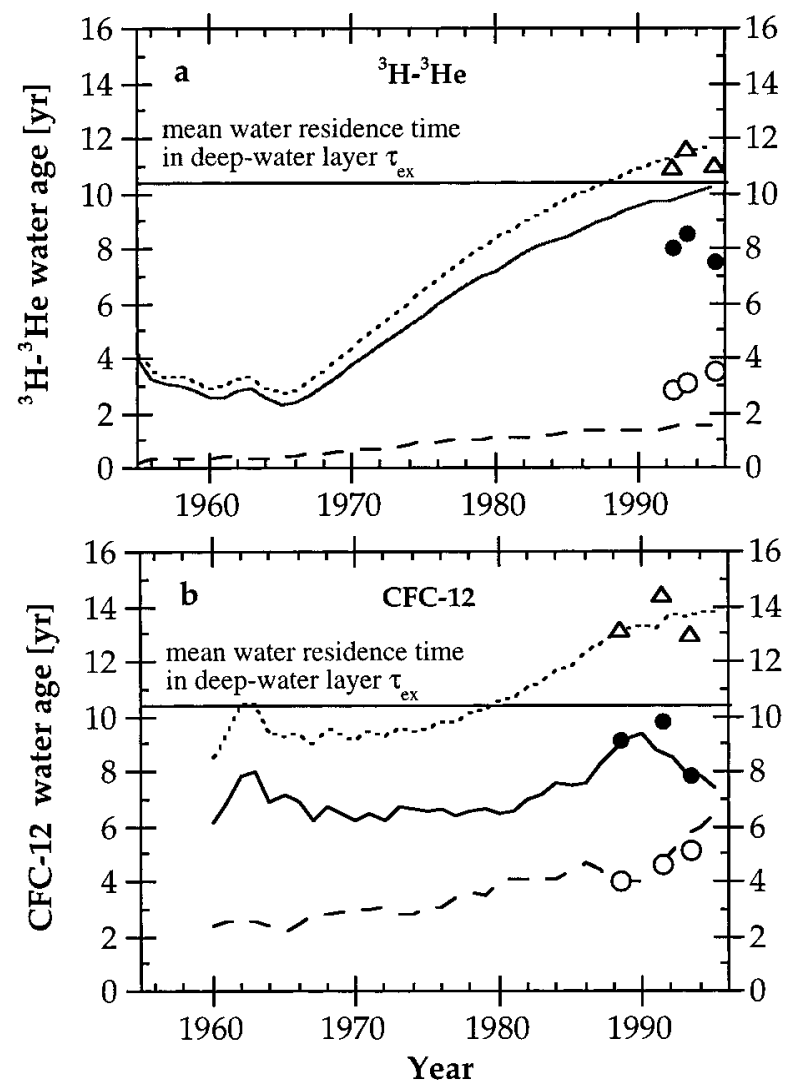

$$
\begin{array}{|lll|}
\hline-- \text { - model (surface layer) } & \mathbf{O} & \text { data (surface layer) } \\
\ldots \ldots . . . \text { model (deep-water layer) } & \Delta & \text { data (deep-water layer) } \\
\text { model (age difference) } & \mathbf{0} & \text { data (age difference) } \\
\hline
\end{array}
$$

FIGURE 7. (a) Temporal evolution of the 'apparent' helium/tritium $w$ ater age in the central basin calculated with eq 9 from the modeled and measured concentrations as show $n$ in Figure 4. The mean $w$ ater residence time in the deep-w ater layer, calculated from the vertical exchange velocity, is $10.4 \mathrm{yr}$ (horizontal line). (b) Temporal evolution of the 'apparent' CFC-12 water age calculated as explained in the text.

increases slowly to about $1.5 \mathrm{yr}$. Note that the difference between the modeled and measured water age in the surface box (Figure 7a) results from the underestimation of the modeled ${ }^{3} \mathrm{He}$ concentration in the surface box (Figure $4 d$ ).

TheCFC-12 water age exhibits a similar temporal evolution (Figure $7 b$ ). As a first approximation the apparent age can be obtained by comparing the measured or modeled CFC-12 concentration with the atmospheric equilibrium concentration. Due to the specific anthropogenic input history, the latter is strongly time-dependent. Theapparent CFC-12 water age is the difference between the time when the sample was taken and the time when the atmospheric equilibrium concentration was equal to the measured or modeled concentration. Sincethe equilibrium concentration of CFC12 is not a monotone function of time (see Figure 5), the mean value of minimum and maximum age is taken. As shown in Figure 7b, the CFC-12 apparent water age in the deep box increased steadily with time and has meanwhile reached about $14 \mathrm{yr}$.

In order to compare these ages with the residence time $\left(\tau_{\mathrm{ex}}\right)$, it should be noted that both measured and modeled water ages of the surface boxes are greater than zero. In fact, excess ${ }^{3}$ Heis al ways aboveatmospheric equilibrium, and CFC12 concentrations in the surface boxes al ways lag behind the changing atmospheric value. Thus, theagedifferencebetween surface and deep-water boxes is the adequate quantity to be compared with the residence time $\tau_{\mathrm{ex}}$, since the water that replaces part of the deep-box volume has non-zero age. The

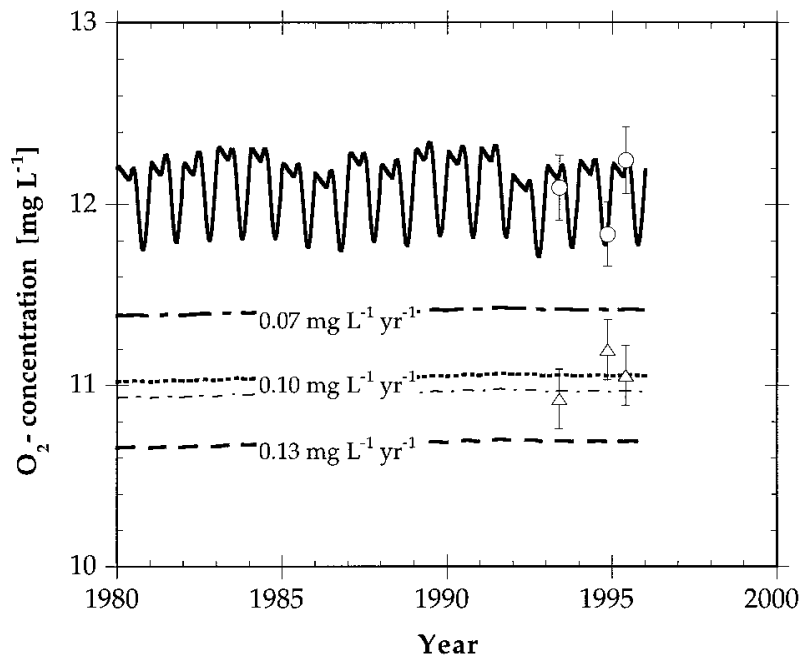

FIGURE 8. Comparison of model calculation and measurement of dissolved oxygen $\left(\mathrm{O}_{2}\right)$ for the surface layer (solid line) and deepw ater layer (dotted line) of the central basin. M ean concentrations calculated from measurements are show $n$ by $\bigcirc$ (surface layer) and $\triangle$ (deep-w ater layer). In the model, vertical exchange velocities are 68,75 , and $64 \mathrm{~m} \mathrm{yr}^{-1}$ for the south, central, and north basins, respectively, and $\mathrm{O}_{2}$ depletion rate is zero in the surface and 0.10 $\mathrm{mg} \mathrm{L}^{-1} \mathrm{yr}^{-1}$ in the deep-w ater layers. Model runs with an oxygen depletion rate of 0.07 and $0.13 \mathrm{mg} \mathrm{L}^{-1} \mathrm{yr}^{-1}$ in the deep-w ater layers are show $n$ by $(---)$ and $(--)$, respectively. The dashed-dotted line $(-\cdot-)$ show $s$ the modeled concentration in the deep-water layer for a depletion rate of $0.10 \mathrm{mg} \mathrm{L}^{-1} \mathrm{yr}^{-1}$ in both the deep-w ater and the surface layers.

procedure by Weiss etal. (1) to correct for the undersaturation of CFC-12 in the surface water when calculating water ages is indeed consistent with the present modeling approach. As shown in Figure 7, the helium/tritium age differences calculated in the central basin is $9.7 \mathrm{yr}$, slightly smaller than the renewal time $\tau_{\text {ex }}$ of $10.4 \mathrm{yr}$. However, the deviation between $\tau_{\text {ex }}$ and the CFC-12 age difference (ca. 8.5yr) is larger. Similar calculations can be made for the other basins (Table 5).

Oxygen Depletion. Once the transport/transformation model iscalibrated, eq 7 can be applied to a non-conservative substance with unknown reaction rate, e.g., to dissolved oxygen. To do so, the last term in both eqs $7 \mathrm{a}$ and $7 \mathrm{~b}$ (production of ${ }^{3} \mathrm{He}$ by radioactive decay of ${ }^{3} \mathrm{H}$ ) is replaced by a term describing the box-specific oxygen depletion rate. We started the simulation of $\mathrm{O}_{2}$ concentrations in 1900 and assumed the initial concentration to be approximately the same as today, which implies that $\mathrm{O}_{2}$ concentrations are at steady state. Simultaneous application of such a model to all basins yields the same depletion rate of $0.10 \pm 0.01 \mathrm{mg}$ $\mathrm{L}^{-1} \mathrm{yr}^{-1}$ for all basins. For this calculation, it is assumed that net oxygen depletion in the surface layers is zero. In Figure 8 the best fit calculation is compared to model runs with (1) the oxygen depletion rate changed by $\pm 30 \%$ and (2) an additional depletion rate of $0.10 \mathrm{mg} \mathrm{L}^{-1} \mathrm{yr}^{-1}$ in all the surface layers. It demonstrates the sensitivity of the model with respect to oxygen depletion.

There is a simple though less sensitive way to cross-check this result. The difference between the average measured oxygen concentration in the surface box of the central basin (12.1 $\mathrm{mg} \mathrm{L}^{-1}$ ) and the corresponding deep-water box (11.1 $\mathrm{mg} \mathrm{L}^{-1}$ ) is $1.0 \mathrm{mg} \mathrm{L}^{-1}$. Dividing this value by the residence time $\tau_{\text {ex }}$ in the central basin (10.4 yr) yields a depletion rate of $0.10 \mathrm{mg} \mathrm{L}^{-1}$. Applying the same approach to the south and north basins, one obtains $\mathrm{O}_{2}$ depletion rates of 0.09 and of $0.13 \mathrm{mg} \mathrm{L}^{-1}$, respectively. Weiss et al. (1) use a similar procedureas above. They base their calculation on the mean water age of all basins below $250 \mathrm{~m}$ depth of $8 \mathrm{yr}$ and on the deep-water oxygen undersaturation relative to a rather arbitrarily assumed oxygen concentration at the surface of 
$12.3 \mathrm{mg} \mathrm{L}^{-1}$. This explains why these authors get a depletion rate of $0.14 \mathrm{mg} \mathrm{L}^{-1} \mathrm{yr}^{-1}$ (Table 5). Note that the uncertainty of these results is fairly large since the method relies on the estimation of a concentration difference from average values of similar size.

As a further method to estimate oxygen depletion rates, water age (calculated from helium/tritium or from CFC-12) and oxygen concentrations are linearly correlated. Theslope of the regression line corresponds to the oxygen depletion rate per unit volume and time. Weiss et al. (1) correlate data from all basins measured below $225 \mathrm{~m}$. Data points from the deepest layers are omitted. Their depletion rate is $0.12 \mathrm{mg}$ $\mathrm{L}^{-1} \mathrm{yr}^{-1}$ (Table 5). Killworth et al. (5) use all data points and get a value between 0.13 and $0.18 \mathrm{mg} \mathrm{L}^{-1} \mathrm{yr}^{-1}$. In both cases the regression is unweighted.

Since oxygen depletion can be decomposed into a volumetric and area-specific component (29), a strict linear correlation between oxygen concentration and water age would indicate that the volumetric oxygen depletion dominates total depletion at most depths. In fact, closer inspection of such correlations show that the data points from the deepest layer of the lake tend to indicate larger depletion rates (6). This is explained by the increasing importance of the area sink due to the large sediment surface per unit volume that characterize the bottom layers of the lake. If the data from the central basin are weighted by the corresponding water volume, the regression yields an oxygen depletion rate of $0.10 \mathrm{mg} \mathrm{L}^{-1} \mathrm{yr}^{-1}$ in accordance with the result from the box model.

Ecological Relevance of Deep-Water Exchange. Given theenormous ecological value of LakeBaikal, it is of uttermost importance to understand the mechanisms that control the oxygen concentration in thelake, which fortunately are (still?) fairly large. On one hand, these are mechanisms related to the production and mineralization of biomass and to the sedimentation of particulate organic carbon to the deep parts of the lake. On the other hand, the physical controlling processes are the renewal rates of deep water in the three basins. Our investigation allows to quantify the renewal rates-although the underlying hydrodynamic forces remain still rather obscure-and thus to indirectly deduce the rate of oxygen consumption due to organic matter degradation.

As a first important conclusion, we were ableto determine fairly precisely the rates of vertical water exchange. Theycan either beexpressed as vertical exchange velocities, exchanged water volumes per year, or mean deep-water residence times (Table 5). The same rates can explain the dynamics of all tracers. As a second point, it was shown that, if tracer distributions are strongly transient, water ages calculated either from CFC concentrations or from ${ }^{3} \mathrm{He} /{ }^{3} \mathrm{H}$ are not identical with the water residence time. In fact, both the CFCs and tritium in Lake Baikal are controlled by the anthropogenic input history, which was extremely dynamic during the last 50 years. Therefore, neither the CFCs nor tritium are presently at steady state in Lake Baikal. Based on the (pseudo) water age calculations shown in Figure 7, we were able to analyze the differences between our water residence times and the water ages given by other investigators.

Thethird point addressed in this paper istheconsumption rate of dissolved oxygen in the deep water of Lake Baikal. By using a regression line for $\mathrm{O}_{2}$ concentration versus CFC-12 water age, Weiss et al. (1) determined an $\mathrm{O}_{2}$ depletion rate for the water below $250 \mathrm{~m}$ of $0.12 \mathrm{mg} \mathrm{L}^{-1} \mathrm{yr}^{-1}$, which is $20 \%$ larger than our value. Applying the same method but using ${ }^{3} \mathrm{H}-{ }^{3} \mathrm{He}$ water ages instead of CFC-12 water ages, Hohmann et al. (6) obtained a similar value for the water below $200 \mathrm{~m}$.

Note that the calculation of oxygen depletion rates from water age suffers from the same problems as the calculation of water age from the non-steady-state distribution of tracers. We have demonstrated that the mean CFC-12 water age difference between deep-water and surface layer underestimates the residence time in the deep-water layer of the central basin by about $30 \%$. Weiss et al. (1) corrected their CFC-12 data to account for the undersaturation in the surface layer. Therefore, their CFC-12 water age essentially corresponds to the difference between the water age measured at a certain depth and that in the surface layer. If we assume that the CFC-12 water age difference underestimates the true residencetime by $30 \%$, the mean oxygen depletion rategiven by Weiss et al. deduced from their CFC-12 water ages should be 30\% larger than the true oxygen depletion rate. Thus, although the oxygen depletion rate given by Weiss et al. is $20 \%$ larger than the value determined by us, their estimation is consistent with the results obtained from our model.

The model predictions for the deep-water renewal rates might give some clues regarding the processes that are the most relevant for the transport of solutes to the deep-water region in LakeBaikal. Because at $300 \mathrm{~m}$ depth the magnitude of the exchange vel ocities (i.e., the transport of water per unit area) predicted by the model are very similar for the three basins, one could argue that the predominant mechanism for deep-water exchange should be a process that is proportional to thearea of the basins. Wind-induced convection suggested first by Weiss etal. issuch a process. Unfortunately, a shift of the mesothermal maximum from $250 \mathrm{~m}$ to more than $400 \mathrm{~m}$ depth required to initiate wind-induced convection at this depth has not yet been observed experimentally. As shown by Walker and Watts (30), severe storms could initiate deep convection, but it is presently unclear whether such storms havethesameprobability to occur in thedifferent basins of Lake Baikal.

Hohmann et al. (2) have identified river-induced convection and mixing of water of slightly different composition at the boundary between basins as important processes of deepwater exchange. These processes cause sinking of water 'around the edge' to the bottom of the basins and could thus explain the characteristic distribution of tracers that often shows water of different composition at the deepest point (see Figure 2). In the central basin-and possibly also in the south basin, though direct observation is missing-the large salinity and turbidity of the rivers Selenga and Barguzin triggers density currents along the bottom. In contrast, deepwater formation in the north basin seems to be related to mixing at the Academician Ridge, which separates the north and central basins.

One of the most important question for the future of Lake Baikal is related to its salt balance (31). Since the renewal rate of deep water seems to depend on subtle density differences between different water masses in the lake and between inlets and lake waters, a change of the lake's salinity may eventually changethe conditions for mixing. Due to the large mean water residence time (about $350 \mathrm{yr}$ ), a possible imbal ance between salt input by rivers and salt output to the sediments and through the outlet changes the salinity in the lake only slowly and may thus remain undetected rather long. Therefore, a program should be started to monitor the salt balance of lake Baikal which would allow-if necessary-the initiation of the adequate countermeasures to restore the salt balance of Lake Baikal.

\section{Acknowledgments}

We thank our Russian colleagues, especially the director of the Limnological Institute in Irkutsk, M. Grachev, for their support during the field work. We are grateful to Werner Aeschbach-Hertig for his critical comments and to Peter Reichert for supporting the application of the simulation tool AQUASIM. This research was conducted within theframework of the Baikal International Centre of Ecological Research (BICER). It was made possible due to the financial support to BICER by the Swiss Federal Institute for Environmental Science and Technology (EAWAG), the Swiss Federal I nstitute 
of Technology (ETH), and the SwissFederal Officefor Science and Education.

\section{Literature Cited}

(1) Weiss, R. F.; Carmack, E. C.; Koropalov, V. M. Nature 1991, 349, 665-669.

(2) Hohmann, R.; Kipfer, R.; Peeters, F.; Piepke, G.; Imboden, D. M.; Shimaraev M. N. Limnol. Oceanogr. In press.

(3) Shimaraev, M. N.; Granin, N. G.; Zhadanov, A. A. Limnol. Oceanogr. 1993, 38, 1068-1072.

(4) Peeters, F.; Piepke, G.; Kipfer, R.; Hohmann, R.; Imboden, D. M. Limnol. Oceanogr. 1997, 41, 1711-1724.

(5) Killworth, P. D.; Carmack, E. C.; Weiss, R. F.; Matear, R. Limnol. Oceanogr. 1996, 41, 1521-1538.

(6) Hohmann, R., Hofer, M.; Kipfer, R.; Peeters, F.; Imboden, D M. J. Geophys. Res. In press.

(7) Craig, H. EOS 1989, 70, 1137.

(8) Kipfer, R.; Aeschbach-Hertig, W.; Hofer, M.; Hohmann, R.; Imboden, D. M.; Baur, H.; Golubev, V.; Klerkx, J. Geochim. Cosmochim. Acta. 1996, 60, 961-971.

(9) Okubo, A. Deep-Sea Res. 1971, 18, 789-802.

(10) Herczeg, A. L.; Imboden, D. M. Limnol. Oceanogr. 1988, 33, 157173.

(11) Unterweger, M. P.; Coursey, B. M.; Schima, F. J.; Mann, W. B. Int. J. Appl. Radiat. Isot. 1980, 31, 611-614.

(12) Schwarzenbach, R. P.; Gschwend, P. M.; Imboden, D. M. Environmental Organic Chemistry, 1st ed.; John Wiley \& Sons, Inc.: New York, 1993.

(13) Krause, W. J. Dtsch. Gewaesserkdl. Mitt. 1980, 24, 2-14.

(14) IAEA. Technical Reports Series No. 165, International Atomic Energy Agency: 1975.

(15) Östlund, H. G. J. Geophys. Res. 1982, 87, 2035-2043.

(16) Roether, W. In Proceedings: Isotopes in Hydrology; International Atomic Energy Agency: 1967, pp 73-79.

(17) Clarke, W. B.; Beg, M. A.; Craig, H. Earth Planet. Sci. Lett. 1969, $6,213-220$

(18) Wanninkhof, R. J. Geophys. Res. 1992, 97, 7373-7382.
(19) Warner, M. J.; Weiss, R. F. Deep-Sea Res. 1985, 32, 1485-1497.

(20) Elkins, J. W.; Thompson, T. M.; Swanson, T. H.; Butler, J. H.; Hall, B. D.; Cummings, S. O.; Fischer, D. A.; Raffo, A. G. Nature 1993, 364, 780-783.

(21) Katz, B. G.; Lee, T. M.; Plummer, L. N.; Busenberg, E. Water Resour. Res. 1995, 31, 1549-1564.

(22) Montzka, S. A.; Butler, J. H.; Myers, R. C.; Thompson, T. M.; Swanson, T. H.; Clarke, A. D.; Lock, L. T.; Elkins, J. W. Science 1996, 272, 1318-1322.

(23) Reichert, P. Water Sci. Technol. 1994, 30, 21-30.

(24) Shimaraev, M. N.; Granin, N. G.; Sherstayankin, P. P. Physical Limnology of Lake Baikal: a review; Irkutsk: Okayama, 1994.

(25) Kipfer, R.; Aeschbach-Hertig, W.; Bauer, H.; Hofer, M.; Imboden, D. M.; Signer, P. Earth Planet. Sci. Lett. 1994, 125, 357-370.

(26) Bullister, J. L.; Weiss, R. F. Deep-Sea Res. 1988, 35, 839-853.

(27) Torgersen, T.; Top, Z.; Clarke, W. B.; Jenkins, W. J.; Broecker, W. S. Limnol. Oceanogr. 1977, 22, 181-193.

(28) Aeschbach-Hertig, W. Ph.D. Dissertation No. 10714, ETH, Zürich, 1994.

(29) Livingstone, D. M.; Imboden, D. M. Can. J. Fish. Aquat. Sci. 1996, 53, 924-932.

(30) Walker, S. J.; Watts, R. G. J. Geophys. Res. 1995, 100, 2271122731.

(31) Imboden, D. M. Coastal Estuarine Studies Ser. In press

(32) Ozima, M.; Podosek, F. A. Noble gas geochemistry; Cambridge University Press: Cambridge, 1983.

(33) Benson, B. B.; Krause, D. J. Chem. Phys. 1976, 64, 689-709.

(34) Clarke, W. B.; Jenkins, W. J.; Top Z. Int. J. Appl. Radiat. Isot. 1976, 27, 515-522.

(35) Benson, B. B.; Krause, D. J. Solution Chem. 1980, 9, 895-909.

Received for review January 21, 1997. Revised manuscript received June 16, 1997. Accepted June $27,1997 .{ }^{\otimes}$

\section{ES9700459}

${ }^{\otimes}$ Abstract published in Advance ACS Abstracts, August 15, 1997. 